\title{
Sliding Component Failure Due to Vibration Damage
}

\author{
Lisa A. Deibler and Donald F. Susan \\ Sandia National Laboratories, Albuquerque, USA
}

Components with surfaces which must be able to slide freely after a period of use were subjected to vibration testing. After vibration testing, some units locked up and were unable to slide. The component consists of two interlocking pins which ride in a housing, as illustrated in Figure 1. During normal operation, the upper pin is pulled up out of the housing where it is free to disconnect from the lower pin. In the post-vibration locked up condition, the upper pin cannot be pulled out of the sleeve.

Several units of varying ages were inspected and it was found that all units which had been subjected to any level of vibration testing showed some amount of wear damage, regardless of whether they locked up after testing. Samples which were not subjected to vibration showed no evidence of similar damage.

Housings are made from PH13-8, H1100 stainless steel while the pins are also PH13-8, but heat treated to the H1050 condition. The pin surface was lubricated with molybdenum-disulfide. The use of the same alloy on mating surfaces was an immediate area of concern for galling and wear damage.

To determine the cause of the lock-up, housings were cut open to remove the pins and surfaces were visually inspected for signs of damage caused by vibration. Figure 2 shows an example of the type of extensive damage visible in a typical housing. A matching pattern of surface wear damage was also observed on the pins. The areas outlined in yellow, red, and purple in Figure 1 were areas of concern for wear damage. The area outlined in yellow near the tip of each pin where they interlock was found to have the most severe damage.

SEM inspection of the wear scars on both the housing and the pins showed the presence of oxide particles, which are indicative of fretting [1]. During fretting, which is often seen on parts subject to vibration, the passive layer on the stainless steel breaks down. This breakdown leads to oxidation and the much harder oxide particles accelerate the wear.

Analysis of the wear scars on both the pins and the housing was performed to determine whether the vibration causes the pin to bond to the sleeve, or if there is an effect of the pulling operation combined with the vibration damage that causes the lock up. SEM images of housings near the top of the lower pin showed evidence that the oxide particles caused by fretting had been smashed into the surface of the housing (Figure 3). The fretting debris was also piled up at the end of a long furrow, indicating that the presence of the wear debris during the attempt to pull out the pin caused the corner of the pin to dig into the housing, which caused the lock up. Once the outside corner of the pin begins to dig into the housing, the geometry of the interlocking pins causes it to lever outwards, digging further into the housing as more force is applied to the pin. In normal operation when there is no wear debris present to cause the outside corner of the pin to begin to stick, the geometry of the interlocking pins would not present any barrier to pull-out. 
Previous to the discovery of lock-up after vibration testing, a prototype new design of the component had been manufactured. Concerns from both mechanical and materials engineers had been addressed in the new design, including changing the pin material to Nitronic 60 coated with a diamond-like carbon (DLC) layer to mitigate potential galling and wear issues. Because of the issues with vibration damage to the old design, the new parts were also subjected to vibration and tested. The new parts also locked up, despite the design and material changes. Inspection of the wear surface showed that the DLC layer was no longer intact, and wear debris was evident on the underlying material.

It was concluded that more mechanical design changes were needed to reduce the tolerances and pre-load the pin connection in order to avoid vibration damage of the sliding interfaces.

\section{[1] Fretting Wear Failures, Failure Analysis and Prevention, Vol 11, ASM Handbook, ASM} International, 2000, p. 922.

[2] The authors acknowledge Amy Allen for SEM characterization. Sandia National Laboratories is a multi-program laboratory managed and operated by Sandia Corporation, a wholly owned subsidiary of Lockheed Martin corporation, for the U.S. Department of Energy's National Nuclear Security Administration under contract DE-AC04-94AL85000.

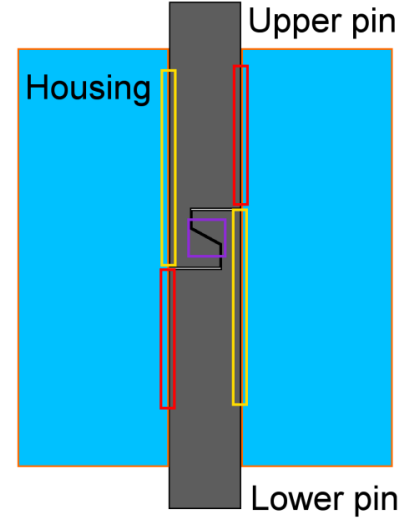

Figure 1. Schematic of component

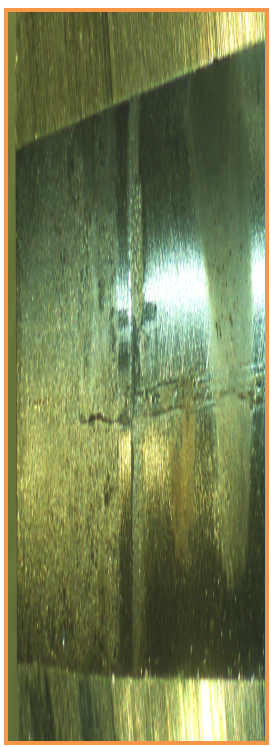

Figure 2. Photograph of wear damage on interior of housing

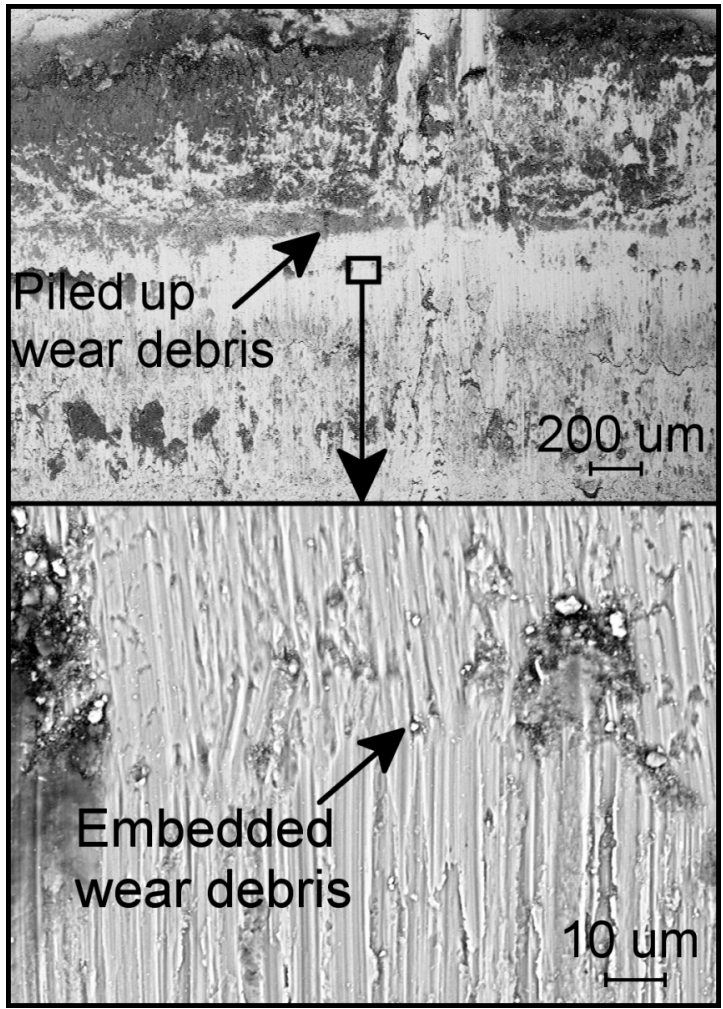

Figure 3. SEM images of piled up and embedded wear debris on housing surface. 